\title{
Consumed Foodstuffs Have a Crucial Impact on the Toxic Activity of Enteropathogenic Bacillus cereus
}

\author{
Claudia Da Riol, Richard Dietrich, Erwin Märtlbauer and Nadja Jessberger* \\ Department of Veterinary Sciences, Faculty of Veterinary Medicine, Ludwig-Maximilians-Universität München, Munich, \\ Germany
}

Enteropathogenic Bacillus cereus cause diarrhea due to the production of enterotoxins in the intestine. To start this process, spores have to be ingested together with contaminated food and survive the stomach passage. In this study, the influence of consumed foodstuffs on spore survival as well as on cytotoxicity toward colon epithelial cells was investigated. Spore survival of 20 enteropathogenic and apathogenic $B$. cereus strains during simulated stomach passage was highly strain-specific and did not correlate with the toxic potential. Survival of three tested strains was strainspecifically altered by milk products. Whereas milk, a follow-on formula and rice pudding had only little influence, spores seemed to be protected by milk products with high fat

OPEN ACCESS

Edited by:

Sophia Johler,

Universität Zürich, Switzerland

Reviewed by:

Mieke Uyttendaele,

Ghent University, Belgium Lucas Wijnands,

National Institute for Public Health and the Environment, Netherlands

*Correspondence:

Nadja Jessberger

N.Jessberger@mh.vetmed.uni-

muenchen.de

Specialty section:

This article was submitted to

Food Microbiology,

a section of the journal

Frontiers in Microbiology

Received: 25 May 2018

Accepted: 31 July 2018

Published: 17 August 2018

Citation:

Da Riol C, Dietrich R, Märtlbauer E and Jessberger N (2018) Consumed Foodstuffs Have a Crucial Impact on the Toxic Activity of Enteropathogenic

Bacillus cereus.

Front. Microbiol. 9:1946.

doi: 10.3389/fmicb.2018.01946 content such as whipped cream and mascarpone. Furthermore, tested milk products decreased the toxic activity of three $B$. cereus strains toward CaCo-2 cells. Investigating the individual components, lactoferrin, a skim milk powder and vitamins $\mathrm{C}, \mathrm{B} 5$ and $\mathrm{A}$ showed the most inhibiting effects. On the other hand, biotin, vitamin B3 and another skim milk powder even enhanced cytotoxicity. Further studies suggested that these inhibiting effects result only partially from inhibiting cell binding, but rather from blocking the interaction between the single enterotoxin components.

Keywords: Bacillus cereus, food infections, stomach passage, survival, cytotoxicity

\section{INTRODUCTION}

Foodborne infections become increasingly attributed to Bacillus cereus (Mead et al., 1999; Scallan et al., 2011; Anonymous, 2013). The Gram-positive, ubiquitous spore-former causes two types of gastrointestinal diseases, the emetic and the diarrheal syndrome (Stenfors Arnesen et al., 2008; Bottone, 2010). Emetic strains produce the heat-stable cyclic dodecadepsipeptide cereulide leading to nausea and vomiting (Agata et al., 1995; Ehling-Schulz et al., 2004; Messelhäusser et al., 2014). The diarrheal form is caused by heat-labile enterotoxins, which are the single protein CytK (cytotoxin K; Lund et al., 2000) and the two three-component complexes Nhe (non-hemolytic enterotoxin; Lund and Granum, 1996; Didier et al., 2016) and $\mathrm{Hbl}$ (hemolysin BL; Beecher et al., 1995). In routine diagnostics, the enteropathogenic potential of a new isolate is so far determined via its ability to produce enterotoxins after growth under standard laboratory conditions (Jessberger et al., 2015). However, in the meantime $B$. cereus food infections are rather understood as multifactorial processes including various steps such as (i) the survival of spores during stomach passage (Clavel et al., 2004; Wijnands et al., 2009; Ceuppens et al., 2012a; Berthold-Pluta et al., 2015), (ii) germination of spores in the small intestine (Clavel et al., 2004; Wijnands et al., 2006, 2007), 
(iii) motility (Ghelardi et al., 2007; Salvetti et al., 2007; Mazzantini et al., 2016), (iv) adhesion of spores and vegetative cells to the intestinal epithelium (Minnaard et al., 2004; Ramarao and Lereclus, 2006), and afterward (v) the production of enterotoxins under intestinal conditions (Jessberger et al., 2017). Furthermore, the impact of complex foodstuffs has also been tested, mainly focusing on bacterial survival. Clavel and coworkers investigated survival of $B$. cereus spores and vegetative cells in artificial stomach fluid after addition of half-skim milk, pea soup or chicken (Clavel et al., 2004). In another study cauliflower, broccoli and okara byproducts limited growth of different foodborne bacteria, amongst them B. cereus (Sanz-Puig et al., 2015). Very little is known about the effect of ingested foodstuffs on the toxic activity of $B$. cereus toward colon epithelial cells. In a first study it was shown that kefir antagonizes the cytopathic effects of $B$. cereus toward $\mathrm{CaCo}-2$ cells without influencing adhesion (Medrano et al., 2008, 2009).

Here we report that consumed milk products or their single components have important impact not only on the survival of $B$. cereus spores during stomach passage, but also on the toxic activity of the $B$. cereus enterotoxins toward colon epithelial cells.

\section{MATERIALS AND METHODS}

\section{Bacterial Strains and Culture Conditions}

In this study, a set of 20 enteropathogenic and apathogenic $B$. cereus strains was used, which has been extensively characterized (Kniehl et al., 2003; Jessberger et al., 2015, 2017). For toxicity studies, a nheABC deletion strain (Tausch et al., 2017) was additionally used. Overnight cultures were grown in CGY medium (casein-glucose-yeast: 2\% casein hydrolysate, $0.6 \%$ yeast extract, $0.2 \%$ ammonium sulfate, $1.4 \%$ $\mathrm{K}_{2} \mathrm{HPO} 4,0.6 \% \mathrm{KH}_{2} \mathrm{PO} 4,0.1 \%$ sodium citrate $\times 2 \mathrm{H}_{2} \mathrm{O}, 0.2 \%$ $\mathrm{MgSO}_{4} \times 7 \mathrm{H} 2 \mathrm{O}, 1 \%$ glucose) at $32^{\circ} \mathrm{C}$ under continuous agitation. For collection of toxin-rich supernatants, cells were treated as previously described (Jessberger et al., 2014).

\section{Cell Lines and Culture Conditions}

CaCo-2 cells were obtained from DSMZ (German Collection of Microorganisms and Cell Cultures, Braunschweig, Germany), cultivated in $80 \mathrm{~cm}^{2}$ culture flasks in a humidified incubator at $37^{\circ} \mathrm{C}$ and $7 \% \mathrm{CO}_{2}$ and passaged $1: 6$ every $3-4$ days. RPMI 1640 medium (with stable glutamine; Biochrom AG) was supplemented with $10 \%$ fetal bovine serum (Biochrom AG).

\section{Spore Preparation}

$2 \times 100 \mathrm{ml}$ fresh Minimal Sporulation Medium $\left(1 \mathrm{M} \mathrm{MgCl}_{2} \times 6\right.$ $\mathrm{H}_{2} \mathrm{O}, 1 \mathrm{M} \mathrm{Ca}\left(\mathrm{NO}_{3}\right)_{2} \times 4 \mathrm{H}_{2} \mathrm{O}, 12.5 \mathrm{mM} \mathrm{ZnCl}_{2}, 2.5 \mathrm{mM}$ $\mathrm{CuCl}_{2}, 2.5 \mathrm{mM} \mathrm{CoCl} 2 \times 6 \mathrm{H}_{2} \mathrm{O}, 2.5 \mathrm{mM} \mathrm{Na}_{2} \mathrm{MoO}_{4} \times 2$ $\mathrm{H}_{2} \mathrm{O}, 5 \mathrm{mM}\left(\mathrm{NH}_{4}\right)_{2} \mathrm{SO}_{4}, 0.066 \mathrm{mM} \mathrm{MnSO}_{4} \times \mathrm{H}_{2} \mathrm{O}, 1 \mathrm{mM}$ $\mathrm{FeSO}_{4}$ and $1 \mathrm{M}$ maltose in bacto nutrient broth (Oxoid); $\mathrm{pH}$ 7.6) were inoculated with $0.5 \%$ overnight culture of each $B$. cereus strain. After 3 days incubation at $30^{\circ} \mathrm{C}$ under continuous shaking, $>80 \%$ spores were present. The cultures were centrifuged $\left(4,000 \mathrm{~g}, 7 \mathrm{~min}, 4^{\circ} \mathrm{C}\right)$ and washed three times in pre-cooled Spore Washing Buffer $\left(2 \mathrm{mM} \mathrm{KH}_{2} \mathrm{PO}_{4}\right.$, $8 \mathrm{mM} \mathrm{K} \mathrm{HPO}_{4}, \mathrm{pH}$ 7.4). Spore suspensions were stored at $4^{\circ} \mathrm{C}$ and further washed once a week for 3 weeks. Immediately before an experiment, spores were washed once again. To determine spore concentrations, suspensions were incubated for $10 \mathrm{~min}$ at $80^{\circ} \mathrm{C}$ to eliminate residual vegetative cells. Serial dilutions of untreated and heat-treated spores were plated on CGY agar plates. After overnight incubation at $32^{\circ} \mathrm{C}$, cfu was determined.

\section{Survival of the Stomach Passage}

Survival of $B$. cereus spores in a medium mimicking the human stomach was investigated following (Clavel et al., 2004). Fifty milliliter pre-warmed medium $\left(4.8 \mathrm{~g} / \mathrm{l} \mathrm{NaCl}, 1.56 \mathrm{~g} / \mathrm{L} \mathrm{NaHCO}_{3}\right.$, $2.2 \mathrm{~g} / \mathrm{l} \mathrm{KCl}, 0.22 \mathrm{~g} / \mathrm{l} \mathrm{CaCl}_{2}$ and $500 \mathrm{U} / 1$ Pepsin; $\mathrm{pH}$ 2) were inoculated with $10^{7} \mathrm{~B}$. cereus spores. If appropriate, different foodstuffs were added in 1:1 ratio to the medium (see below). The mixture was incubated for $6 \mathrm{~h}$ at $37^{\circ} \mathrm{C}$ under smooth shaking. $\mathrm{pH} 2$ was maintained during the entire experiment. Every hour $300 \mu \mathrm{l}$ samples were taken and incubated at $80^{\circ} \mathrm{C}$ for $10 \mathrm{~min}$. Subsequently, serial dilutions were plated on CGY agar. After overnight incubation at $32^{\circ} \mathrm{C}$, cfu was determined and compared with the inoculum, which was also plated on CGY agar.

\section{Food Preparation}

To assess the impact of foodstuffs on spore survival, different milk products were tested: UHT milk 1.5\%, UHT milk 3.5\%, UHT milk 1.5\% lactose-free, UHT whipped cream (30\% fat content), mascarpone (composition: pasteurized cream, pasteurized milk, acidifier: citric acid, rennet, lactic acid bacteria; $80 \%$ fat in dry mass), a baby follow-on formula (composition: see Table 1) and rice pudding (composition: milk 3\%, $\mathrm{H}_{2} \mathrm{O}$, rice, sugar, modified starch, salt, aroma, no additional fruits). All products were pre-tested for total bacterial counts (according to DIN 10192) and presumptive B. cereus (according to DIN 10198). Only contamination-free products were used for the experiments. The baby follow-on formula (14.1 g) was dissolved in $90 \mathrm{ml}$ a. dest. according to the instructions of the manufacturer. The rice pudding was homogenized for $2 \mathrm{~min}$ in a stomacher homogenizer. Finally, $50 \mathrm{~g}$ or $\mathrm{ml}$ food were mixed in a 1:1 ratio with the stomach medium (Clavel et al., 2004). After that, $\mathrm{pH}$ values were adjusted to 2 by using $5 \mathrm{M} \mathrm{HCl}$.

\section{WST-1 Bioassay}

WST-1 bioassays were performed on CaCo-2 cells as described earlier (Jessberger et al., 2017). Briefly, serial dilutions of the culture supernatants were applied to 96 well plates in RPMI 1640 medium $(100 \mu \mathrm{l} /$ well). Food components were added in constant concentration to the medium as indicated in Table 1. Subsequently, $2 \times 10^{4} 3$ day old CaCo- 2 cells/well $(100 \mu \mathrm{l})$ were applied. After $24 \mathrm{~h}$ incubation at $37^{\circ} \mathrm{C}$ and $7 \% \mathrm{CO}_{2}$, cell viability was determined by addition of WST-1 (Roche diagnostics). $\mathrm{OD}_{450 \mathrm{~nm}}$ was recorded in a Tecan infinite $\mathrm{F} 50$ photometer. Dose-response curves and thus 50\% lethal concentrations were calculated with Magellan software and are shown as reciprocal titers. 


\section{Propidium lodide (PI) Influx Tests}

To assess pore formation in the membranes of CaCo-2 cells, propidium iodide influx studies were performed as previously described (Jessberger et al., 2014, 2017). Briefly, $4 \times 10^{4} 3$ day old CaCo-2 cells were grown overnight in 96 well plates. For consecutive application of foods and B. cereus supernatants, RPMI 1640 medium was removed and $200 \mu \mathrm{l}$ fresh medium containing food components in concentrations as stated in Table 1 were added for $1 \mathrm{~h}$. After three washing steps in RPMI 1640 medium, $200 \mu \mathrm{l}$ fresh medium were added containing $10 \mu \mathrm{g} / \mathrm{ml}$ PI (Sigma-Aldrich) and 1:40 dilutions of the culture supernatants. For consecutive application of recombinant $\mathrm{Hbl}$ proteins (Tausch et al., 2017), stock solutions $(1.5 \mathrm{pmol} / \mu \mathrm{L})$ of each component were mixed 1:40 in RPMI 1640 medium (alone or with food components in concentrations as stated in Table 1). After application of $\mathrm{Hbl} \mathrm{B}$ and $\mathrm{L} 1, \mathrm{CaCo}-2$ cells were washed three times in RPMI 1640 medium. Hbl L2 was applied in medium additionally containing $10 \mu \mathrm{g} / \mathrm{ml}$ PI. Immediately after addition of PI, fluorescence was measured in a Victor 1420 multilabel counter (Perkin Elmer) for $4 \mathrm{~h}$ every $2.5 \mathrm{~min}$ (excitation: $530 \mathrm{~nm}$; emission: $616 \mathrm{~nm}$; excitation time: $1 \mathrm{~s}$; excitation strength: 20,000).

TABLE 1 | Foodstuffs and food components used in WST-1 bioassays in this study.

\begin{tabular}{|c|c|c|c|c|c|c|c|}
\hline \multirow[b]{2}{*}{ Milk products } & \multirow[t]{2}{*}{ Concentration in WST } & \multirow[t]{2}{*}{ Influence on toxicity } & \multicolumn{5}{|c|}{$\begin{array}{c}\text { Effect in ElA } \\
\text { NheA NheB Hbl L2 Hbl L1 Hbl B }\end{array}$} \\
\hline & & & & & & & \\
\hline UHT milk 1.5\% & $2 \%$ & $\downarrow$ & + & - & - & + & + \\
\hline UHT milk 3.5\% & $2 \%$ & $\downarrow$ & + & - & - & + & + \\
\hline UHT lactose-free milk $1.5 \%$ & $2 \%$ & $\downarrow$ & + & - & - & + & - \\
\hline Baby follow-on formula & $3.925 \mathrm{mg} / \mathrm{ml}$ & $\downarrow$ & + & - & - & + & + \\
\hline \multicolumn{8}{|l|}{ Milk components } \\
\hline$\alpha$-casein & $0.2 \%$ & $\downarrow$ & - & - & - & - & + \\
\hline$\beta$-casein & $0.2 \%$ & - & n.d. & n.d. & n.d. & n.d. & n.d. \\
\hline$\kappa$-casein & $0.2 \%$ & - & n.d. & n.d. & n.d. & n.d. & n.d. \\
\hline$\alpha$-lactalbumin & $0.2 \%$ & $\downarrow$ & - & - & - & - & - \\
\hline$\beta$-lactoglobulin & $0.2 \%$ & - & n.d. & n.d. & n.d. & n.d. & n.d. \\
\hline Lactoferrin & $0.2 \%$ & $\downarrow$ & - & - & - & - & - \\
\hline \multicolumn{8}{|l|}{ Follow-on formula components } \\
\hline Skim milk powder I & $5 \mathrm{mg} / \mathrm{ml}$ & $\downarrow$ & - & - & - & + & + \\
\hline Skim milk powder II & $5 \mathrm{mg} / \mathrm{ml}$ & - & n.d. & n.d. & n.d. & n.d. & n.d. \\
\hline Skim milk powder III & $5 \mathrm{mg} / \mathrm{ml}$ & $\uparrow$ & - & - & - & + & - \\
\hline Starch & $9.06 \mu \mathrm{g} / \mathrm{ml}$ & - & n.d. & n.d. & n.d. & n.d. & n.d. \\
\hline Calcium carbonate & $5 \mu \mathrm{g} / \mathrm{ml}$ & - & n.d. & n.d. & n.d. & n.d. & n.d. \\
\hline Vitamin C (L-ascorbic acid) & $364 \mu \mathrm{g} / \mathrm{ml}$ & $\downarrow$ & - & - & - & - & - \\
\hline Potassium chloride & $1.9 \mathrm{mg} / \mathrm{ml}$ & - & n.d. & n.d. & n.d. & n.d. & n.d. \\
\hline Ferric lactate & $9.77 \mu \mathrm{g} / \mathrm{ml}$ & - & n.d. & n.d. & n.d. & n.d. & n.d. \\
\hline Vitamin $E^{*}$ & $1.19 \mathrm{mg} / \mathrm{ml}$ & - & n.d. & n.d. & n.d. & n.d. & n.d. \\
\hline Zinc sulfate & $50.88 \mu \mathrm{g} / \mathrm{ml}$ & - & n.d. & n.d. & n.d. & n.d. & n.d. \\
\hline Vitamin B5 (calcium-D-panthotenate) & $1.24 \mathrm{mg} / \mathrm{ml}$ & $\downarrow$ & - & - & - & - & - \\
\hline Copper sulfate & $2 \mu \mathrm{g} / \mathrm{ml}$ & - & n.d. & n.d. & n.d. & n.d. & n.d. \\
\hline Vitamin A (retinol)* & $3.91 \mu \mathrm{g} / \mathrm{ml}$ & $\downarrow$ & + & - & - & - & - \\
\hline Vitamin B1 (thiamine) & $316 \mu \mathrm{g} / \mathrm{ml}$ & - & n.d. & n.d. & n.d. & n.d. & n.d. \\
\hline Vitamin B6 (pyridoxine hydrochloride) & $1.319 \mathrm{mg} / \mathrm{ml}$ & - & n.d. & n.d. & n.d. & n.d. & n.d. \\
\hline Manganese sulfate & $0.625 \mu \mathrm{g} / \mathrm{ml}$ & - & n.d. & n.d. & n.d. & n.d. & n.d. \\
\hline Potassium iodate & $788 \mu \mathrm{g} / \mathrm{ml}$ & - & n.d. & n.d. & n.d. & n.d. & n.d. \\
\hline Folic acid & $125 \mu \mathrm{g} / \mathrm{ml}$ & - & n.d. & n.d. & n.d. & n.d. & n.d. \\
\hline Vitamin K1 (phytomenadione)* & $615 \mu \mathrm{g} / \mathrm{ml}$ & - & n.d. & n.d. & n.d. & n.d. & n.d. \\
\hline Sodium selenate & $4.14 \mu \mathrm{g} / \mathrm{ml}$ & - & n.d. & n.d. & n.d. & n.d. & n.d. \\
\hline Biotin & $5 \mu \mathrm{g} / \mathrm{ml}$ & $\uparrow$ & - & - & - & - & - \\
\hline Vitamin D3* & $3.91 \mu \mathrm{g} / \mathrm{ml}$ & - & n.d. & n.d. & n.d. & n.d. & n.d. \\
\hline Vitamin B3 (nicotinic acid) & $313 \mu \mathrm{g} / \mathrm{ml}$ & $\uparrow$ & - & - & - & - & - \\
\hline
\end{tabular}

In general, $2 \%$ milk was added to the cell culture medium, milk components were adjusted to $0.2 \%$. Follow-on formula components were initially added in the highest concentration which was solvable, did not affect the CaCo-2 cells and did not interfere with the photometric measurement. ${ }^{*}$ Stock solution in $70 \%$ ethanol. $\downarrow$ : decrease of toxic activity. $\uparrow$ increase of toxic activity. + Altered toxin titers in EIA. - Low or no influence on toxicity and ElA results. n.d., not determined. 


\section{Enzyme Immunoassays (EIAs)}

Sandwich enzyme immunoassays for the detection of enterotoxin components were carried out as previously described (Dietrich et al., 1999, 2005; Jessberger et al., 2015, 2017; Tausch et al., 2017). Food components were dissolved in PBS in concentrations as stated in Table $\mathbf{1}$ and mixed 1:1 with B. cereus culture supernatants. The following antibodies were used for detection: $5 \mu \mathrm{g} / \mathrm{ml} \mathrm{mAb} 2 \mathrm{~B} 11 / 1 \mathrm{E} 11-\mathrm{HRP}$ 1:4,000 (NheB), $2.5 \mu \mathrm{g} / \mathrm{ml} \mathrm{mAb}$ 1G4/2G11-HRP 1:2,000 (NheA), $10 \mu \mathrm{g} / \mathrm{ml} \mathrm{mAb} \mathrm{1A12/1H9-HRP}$ 1:2,000 (Hbl L2), $5 \mu \mathrm{g} / \mathrm{ml} \mathrm{mAb}$ 1E9/1G8-HRP 1:2,000 (Hbl L1), and $2.5 \mu \mathrm{g} / \mathrm{ml} \mathrm{mAb}$ 1D12/1B8-HRP 1:2,000 (Hbl B). Titers are defined as the reciprocal of the highest dilutions resulting in an absorbance value of $\geq 1.0$. Results were compared according to those titers and are summarized in Table 1.

\section{RESULTS}

\section{Survival of the Stomach Passage Is Highly Strain-Specific}

In a preliminary experiment, $20 \mathrm{~B}$. cereus strains were tested for their ability to survive conditions mimicking the stomach (Clavel et al., 2004). The strain set consists of enteropathogenic (highly toxic) and apathogenic or low toxic isolates, which have previously been characterized in detail (Kniehl et al., 2003; Jessberger et al., 2015, 2017). Spore preparations were used for inoculation, as vegetative cells did not survive under the chosen conditions (data not shown). Spores of all 20 strains were able to survive for at least $1 \mathrm{~h}$ (Figure 1). Highest rates were found for WSBC 10035 (highly toxic; 9.6\%) as well as for INRA A3 (low toxic), RIVM BC 964 (highly toxic) and 7/27/S (highly toxic) (all $>4 \%$ ). RIVM BC 126 (highly toxic) showed poorest survival (0.02\%). After $6 \mathrm{~h}$, survival of 19 strains dropped to $<1 \%$ (Figure 1). Thus, the ability of B. cereus spores to resist the stomach conditions depends massively on the individual strain. Furthermore, survival does not correlate with the toxic potential of an isolate.

\section{Protection of B. cereus Spores by Foodstuffs}

To investigate the impact of ingested foodstuffs on spore survival, the highly toxic reference strain NVH 0075-95 (nhe+, low survival rate) was chosen, as well as the two low toxic strains F528/94 (nhe+, hbl+) and MHI 226 (nhe+) (Jessberger et al., 2015), both with medium survival rates as shown in Figure 1. As we were especially interested in milk and milk products, we tested milk $1.5 \%$, milk $3.5 \%$, lactose-free milk $1.5 \%$, whipped cream, mascarpone, a baby follow-on formula and rice pudding. As above, spore survival was tested for $6 \mathrm{~h}$. The effect of the foodstuffs on spore survival was highly variable depending on the individual B. cereus strain (Figure 2). While reference strain NVH 0075-95 showed comparably low survival rates with all foodstuffs tested (Figure 2A), spores of strain F528/94 were protected by whipped cream and especially mascarpone (Figure 2B). Mascarpone also significantly increased survival of spores of strain MHI 226, while lactose-free milk, the follow-on formula and rice pudding even seemed to impair spore survival (Figure 2C). Two mascarpone samples were investigated. Mascarpone I, which protected the spores even more clearly, was at the moment the experiment was conducted already expired by 2 weeks, while mascarpone II was within the best before date. Generally it can be postulated that, though highly strain-specific, $B$. cereus spores survive the stomach environment more easily in the presence of more complex milk products with higher fat content.

\section{Food Components Influence the Toxic Activity of $B$. cereus Supernatants}

To show that foodstuffs cannot only influence spore survival, but also the activity of the B. cereus enterotoxins, WST-1 bioassays were performed on CaCo-2 cells. Here, mascarpone, whipped cream and rice pudding could not be further investigated due to the high susceptibility of the cells and the test system. The remaining foodstuffs were added to the test in concentrations as stated in Table 1. Figure 3 shows that the toxic activity of three $B$. cereus strains was significantly decreased by milk and the baby follow-on formula. Toxicity titers of reference strain F837/76, which secretes both enterotoxins, Nhe and Hbl, were halved in the presence of milk $1.5 \%$, milk $3.5 \%$ and lactose-free milk and even reduced to a minimum in the presence of the baby followon formula (Figure 3A). Toxicity of strain F837/76 $\Delta$ nheABC, which is able to produce only $\mathrm{Hbl}$, was also reduced. Again, the baby follow-on formula had the strongest impact (reduction approximately $66 \%$ ), whereas lactose-free milk reduced toxicity by only 33\% (Figure 3C). The same milk products decreased the toxic activity of Nhe reference strain NVH 0075-95, which was generally lower than the other two strains in this experiment, by approximately $40 \%$ (Figure $3 \mathrm{E}$ ). These results suggest that haemolysin BL might be more affected by the presence of foodstuffs than the non-hemolytic enterotoxin.

Following these results, we were further interested which food components might be responsible for the reduction of the toxic effects. The tested substances are summarized in Table $\mathbf{1}$. As the baby follow-on formula had most impact on strain F837/76 (Figure 3A), this strain was used for investigating its ingredients. All tested substances are summarized in Table $\mathbf{1 .}$ Further components, fish oil and fruit powder, could not be tested. Substances with significant impact on cytotoxicity are shown in Figure 3B. A skim milk powder, vitamin C, vitamin B5 and vitamin A decreased the toxic activity, while enhanced toxicity titers were detected with skim milk powder III, biotin and vitamin B3. Milk proteins showed only minimal effects on the toxic activity of strains F837/76 and NVH 0075-95 (data not shown). On the other hand, $\alpha$-casein, $\alpha$-lactalbumin and especially lactoferrin decreased toxicity of the nhe $A B C$ deletion strain (Figure 3D).

\section{Foodstuffs Partially Block Cell Binding, but Rather Interfere With the Interaction of the Single Toxin Components}

To get a first idea about the mechanism by which the different food components might impede enterotoxic activity, selected 

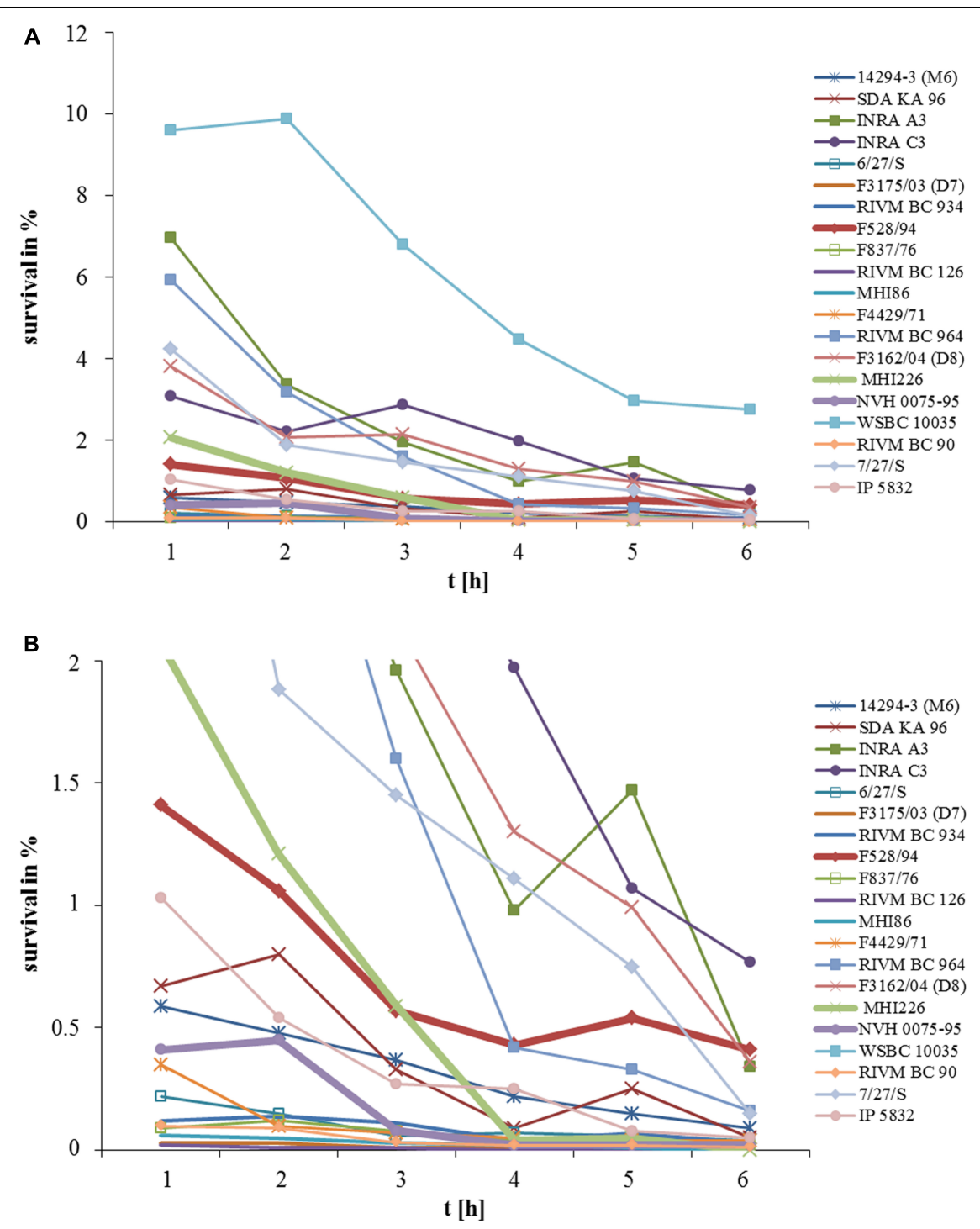

FIGURE 1 | Survival of 20 B. cereus strains in medium simulating the stomach passage. Medium (Clavel et al., 2004) was inoculated with $10^{7}$ spores. Every hour, samples were taken and cfu was determined. (A) Survival is shown as \% of the inoculum. (B) Enlargement of data points obtained for survival rates between 0 and 2\%.

foods and toxin-containing B. cereus supernatants were applied to $\mathrm{CaCo}-2$ cells consecutively. For consecutive application, PI influx tests are more suitable than WST-1 bioassays. Here, poreforming activity of the enterotoxins can be observed in real time. Pore formation of F837/76 supernatant was rarely affected by pre-incubation with the different foodstuffs, only milk $3.5 \%$ and the baby follow-on formula resulted in delayed and less increase of fluorescence (Figure 4A), indicating that these two products might partially block the cell surface toward enterotoxin binding.

Simultaneously, food components with effect on toxic activity were mixed with the $B$. cereus supernatant in enzyme immunoassays detecting the single enterotoxin proteins. Certain food components altered the reciprocal titers obtained for NheA, $\mathrm{Hbl} \mathrm{L1}$ and $\mathrm{Hbl} \mathrm{B}$. These data are summarized in Table 1. The results indicate that some enterotoxin components might be blocked by the foodstuffs, and thus binding of the specific mAbs is altered. Hence, the interaction between the single enterotoxin components might also be influenced.

To investigate this in detail, the recombinant $\mathrm{Hbl}$ components B, L1 and L2 (Tausch et al., 2017) were applied in PI influx tests consecutively. One $\mathrm{Hbl}$ protein at a time was applied in RPMI 1640 medium mixed with selected foods. Milk 3.5\%, the follow-on formula and lactoferrin showed the most impact on pore-forming activity (Figure 4B). For approximately $70 \mathrm{~min}$, milk $3.5 \%$ had no influence on $\mathrm{rHbl} \mathrm{L2}$, only a late decline in fluorescence was observed. Activities of $\mathrm{rHbl} \mathrm{B}$ and $\mathrm{Ll}$ were affected similarly. The follow-on formula hindered poreformation most clearly, whatever $\mathrm{Hbl}$ component it was applied with. On the contrary, lactoferrin had the strongest impact on rHbl B activity. 


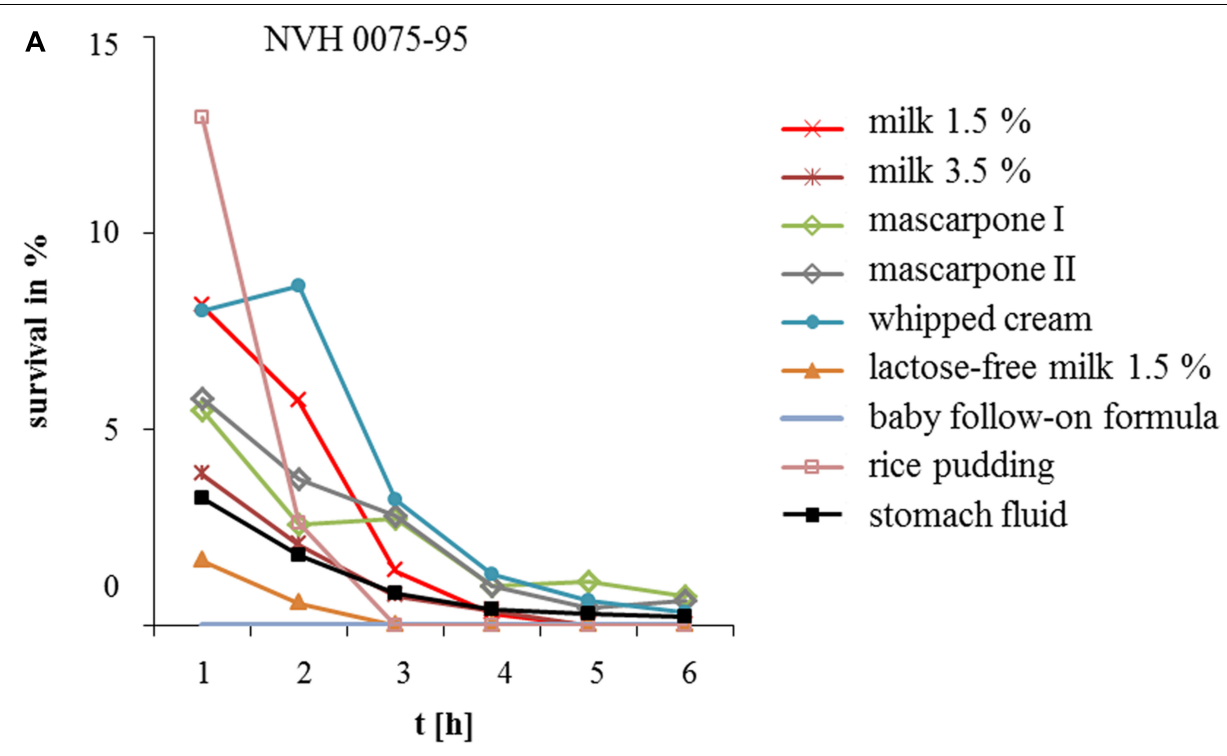

B

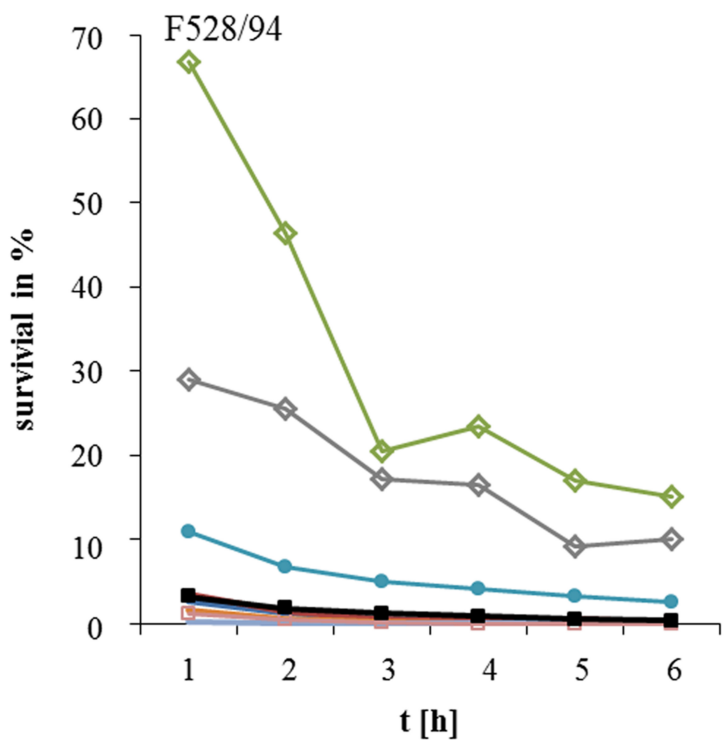

C

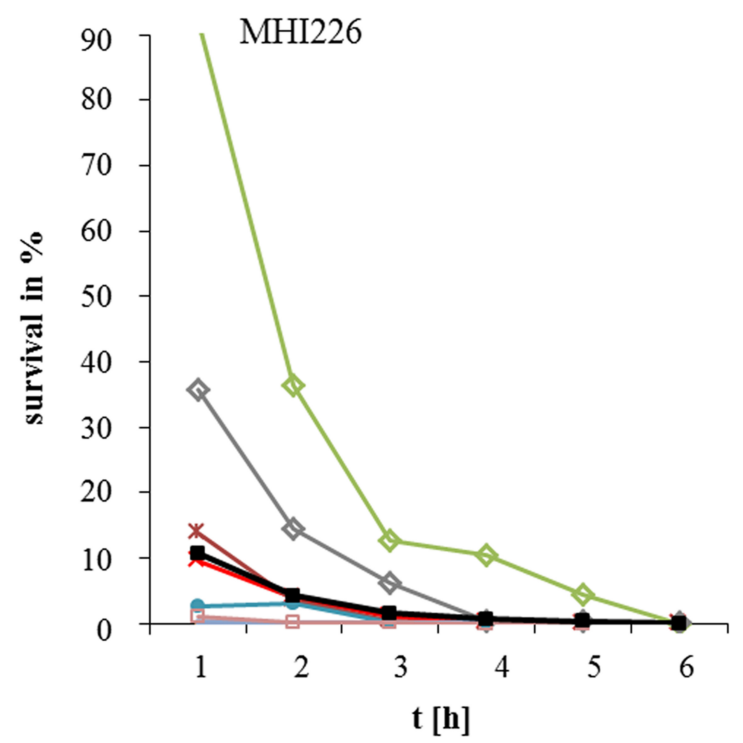

FIGURE 2 | Survival of B. cereus in stomach medium with different foodstuffs. (A) B. cereus strain NVH $0075-95$ (highly toxic, highly susceptible toward the stomach medium, see Figure 1 and Jessberger et al., 2015, 2017). (B) Strain F528/94 (low toxic, medium susceptibility toward the stomach medium, see Figure 1 and Jessberger et al., 2015, 2017). (C) Strain MHI 226 (low toxic, medium susceptibility toward the stomach medium, see Figure 1 and Jessberger et al., 2015, 2017 ). Strains were grown for $6 \mathrm{~h}$ in stomach fluid (Clavel et al., 2004) as control and additionally with milk (1.5 and $3.5 \%$ fat), 1.5\% lactose-free milk, whipped cream, mascarpone, baby follow-on formula and rice pudding. Survival rates are comparatively shown. Survival is depicted as $\%$ of the inoculum.

\section{DISCUSSION}

In this study we demonstrated a significant impact of the consumed food on spore survival and cytotoxic activity of $B$. cereus. Although highly strain-specific, spores seemed to be protected from stomach medium and low $\mathrm{pH}$ by more complex milk products with high fat content (Figures 1, 2). In a previous study is has already been shown that the number of spores incubated in gastric medium at low $\mathrm{pH}$ remained stable when half-skim milk or chicken were added (Clavel et al.,
2004). Ceuppens and coworkers grew B. cereus in lasagne verde (Ceuppens et al., 2012b,c) before simulating the human upper gastrointestinal tract. As in our study, vegetative cells could not survive these conditions. Furthermore, the authors concluded that food can strain-specifically benefit spore survival (Ceuppens et al., 2012c). As a Gram-positive bacterium, B. cereus is highly sensitive toward bile salts, which can be relieved by different food components (Clavel et al., 2004; Ceuppens et al., 2012c).

The influence of food on the toxic activity of $B$. cereus is to date best investigated for kefir. It has been shown in cell toxicity 


\section{A}

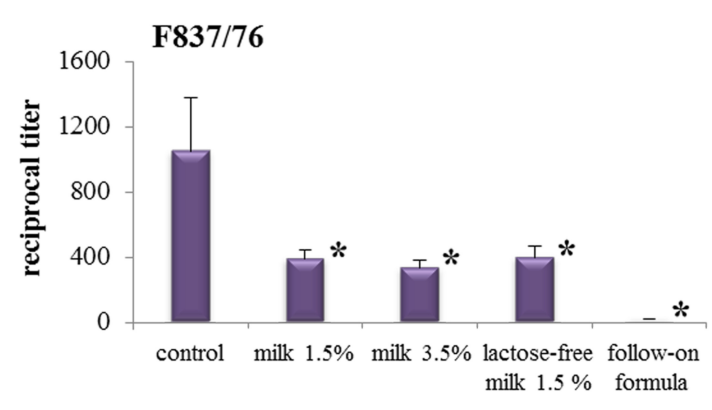

C

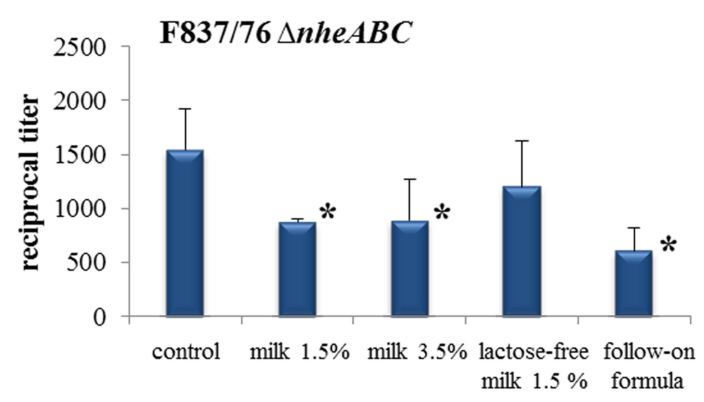

E

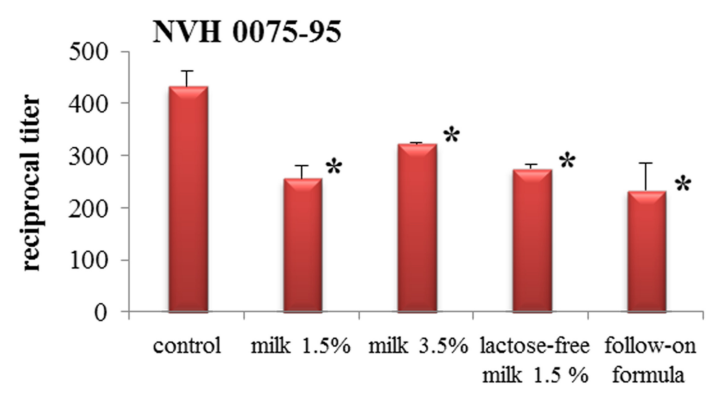

B

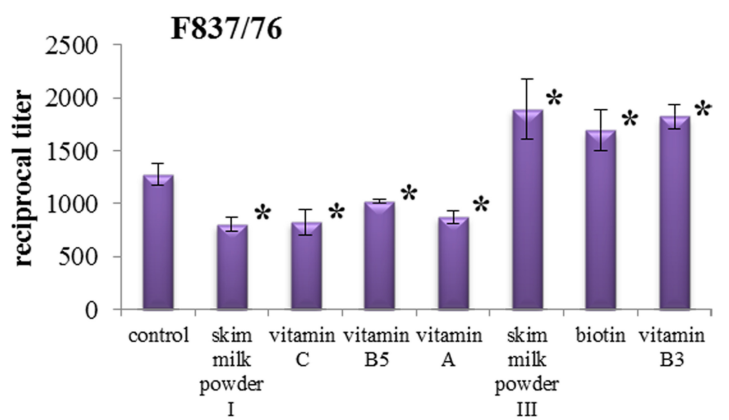

D

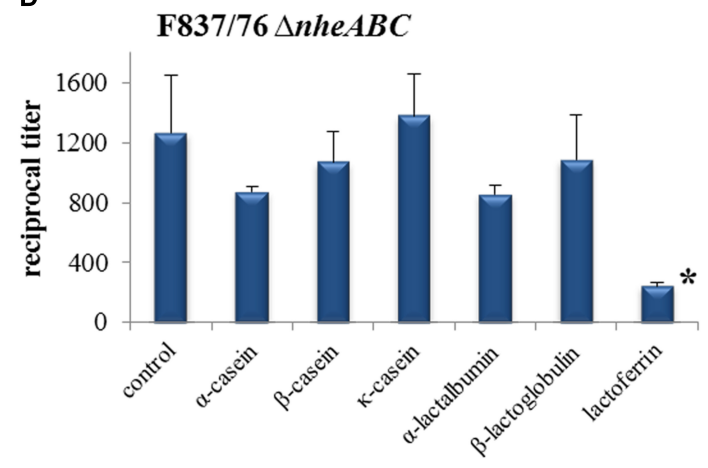

FIGURE 3 | Cytotoxic activity of $B$. cereus culture supernatants in the presence of different milk products. Results of WST-1 bioassays performed on CaCo-2 cells are shown as reciprocal titers. In these experiments, $B$. cereus supernatants were applied as serial dilutions, while foodstuffs were added in constant concentrations as stated in Table 1. (A) Reference strain F837/76 (nhe+, hb/+) with foods. (B) Cytotoxicity of strain F837/76 under addition of different follow-on formula ingredients. The positive control differs from that in $\mathbf{A}$, as it was obtained in an independent approach. (C) $n h e A B C$ deletion mutant of F837/76 ( $h b /+)$.

(D) Cytotoxicity of the $n h e A B C$ deletion strain under addition of milk proteins. The positive control differs from that in (C), as it was obtained in an independent approach. (E) Reference strain NVH 0075-95 (nhe+). *Significant difference (P-value < 0.05). Data were statistically analyzed using the column statistics program (unpaired $t$-test, 95\% confidence interval) of Graph Pad Prism version 5.00 (GraphPad Software, La Jolla, CA, United States).

assays, apoptosis and necrosis studies that kefir strain-specifically protects CaCo-2 cells from $B$. cereus culture supernatants (Medrano et al., 2008). Furthermore, cells "coated" with kefir were better preserved from detachment, F-actin disorganization and microvilli effacement. Kefir also modified the distribution of adhered B. cereus. The authors further demonstrated that the exopolysaccharide kefiran is able to interact with both eukaryotic cells and B. cereus (Medrano et al., 2009). In our study, milk and a baby follow-on formula strain-specifically reduced the toxic activity of B. cereus culture supernatants (Figure 3). Of the single milk components, lactoferrin showed the most inhibiting effects (Figure 3D). This iron-binding glycoprotein is an important component of the innate immune system, which has been reported to inhibit bacterial growth (Sato et al., 1999; Valenti et al., 2004; Ochoa and Cleary, 2009; Luna-Castro et al., 2014) as well as adhesion, invasion, motility, aggregation and biofilm formation (Valenti et al., 2004; Valenti and Antonini, 2005; Ochoa and Cleary, 2009; Luna-Castro et al., 2014). By binding LPS, it prevents inflammation, sepsis and gastroenteritis caused by enteric viruses, Salmonella, Shigella, or E. coli (Ochoa and Cleary, 2009; Latorre et al., 2010). It is also able to counteract cholera toxin by decreasing binding of the toxin to GM1-ganglioside on the target cell surface (Rivera et al., 2013). Cholera toxin belongs to the bacterial $\mathrm{AB}_{5}$ toxins (Merritt and Hol, 1995), which exhibit a mode of action different from the pore-forming B. cereus enterotoxins. Nevertheless, some evidence has been found that 

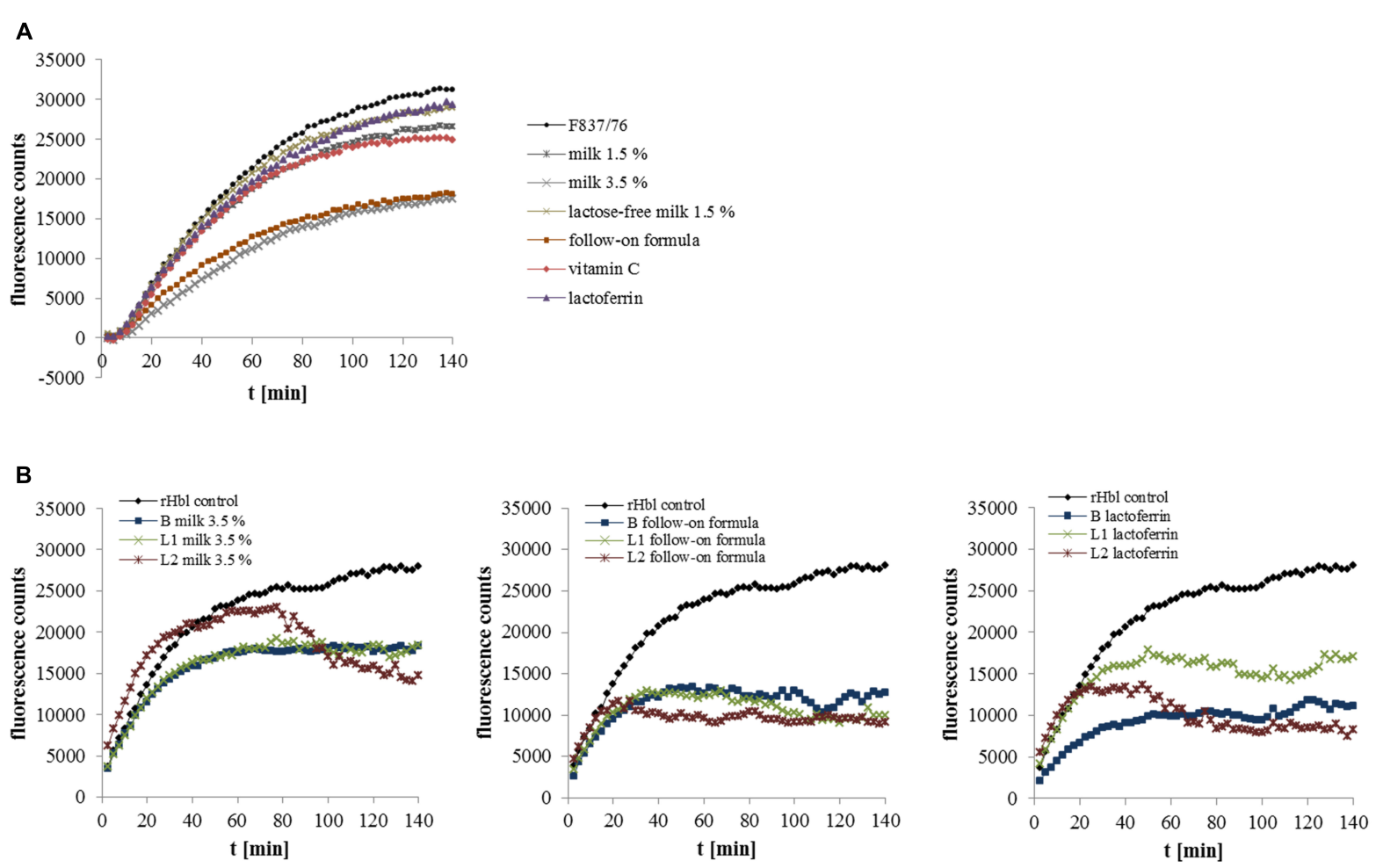

FIGURE 4 | Pore forming activity of $B$. cereus enterotoxins determined in propidium iodide influx tests. (A) CaCo-2 cells were pre-incubated for $1 \mathrm{~h}$ with the different food and food components and washed three times in RPMl 1640 medium. Subsequently, supernatant of strain F837/76 was added in 1:40 dilution. (B) The recombinant $\mathrm{Hbl}$ components B, L1 and L2 were applied consecutively for $1 \mathrm{~h}$ each, either in RPMl 1640 medium or in the medium containing the food components in concentrations as shown in Table 1. After application of r $\mathrm{Hbl} \mathrm{B}$ and L1, CaCo-2 cells were washed three times. Pl influx is shown as increase of fluorescence per time.

lactoferrin can also act as serine protease (Valenti et al., 2004), and might thus inhibit the highly protease-sensitive $B$. cereus enterotoxins. Of the single follow-on formula components, a skim milk powder and vitamins C, B5 and A showed inhibitory effects in our study (Figure 3B). Vitamin $C$ is an antioxidant with important immunological function (Ströhle et al., 2011; Chambial et al., 2013; Sorice et al., 2014). A decreased risk of gastric diseases, also with reference to Helicobacter pylori infections, has been described (Tabak et al., 2003). Essential immunological functions are also attributed to vitamin A (Ströhle et al., 2011; Brown and Noelle, 2015; Sirisinha, 2015). Alpsoy and coworkers showed protective effects of vitamins A, C and E against aflatoxin B (Alpsoy et al., 2009a,b; Alpsoy and Yalvac, 2011). Furthermore, vitamin C decreases endothelial cell permeability (May and Qu, 2010, 2011), which might counteract the pore-forming B. cereus enterotoxins.

In this study the different foods only partially blocked the enterotoxins from binding to the target cell surface (Figure 4A). We rather found first evidence that the interaction between the single toxin components is disrupted. Under addition of different foods, detection of the single enterotoxin components in enzyme immunoassays was altered (see Table 1). The variability in binding of the specific mAbs is possibly due to blocking of the enterotoxin proteins by food components. Thus, it is, similarly, conceivable that such a "food-coated" enterotoxin protein is no longer able to interact with the other toxin components. This assumption was supported as foods also interfered with the sequential binding of recombinant $\mathrm{Hbl}$ components to the cell surface (Figure 4B).

$B$. cereus enterotoxins are unique among the pore-forming toxins, as they assemble from three different proteins. A specific binding order, i.e., NheC-B-A, is necessary for toxicity of the non-hemolytic enterotoxin (Sastalla et al., 2013). First, NheC and $\mathrm{B}$, which already form complexes in solution, attach to the cell surface (Didier et al., 2012; Heilkenbrinker et al., 2013). In a second step, NheA binds, undergoes conformational changes and completes the pore (Didier et al., 2016). If NheA is blocked, which our data point to, the pore cannot be completely formed and its toxic effect is hindered. Similarly, the specific binding order B-L1-L2 is necessary for $\mathrm{Hbl}$ toxicity (Sastalla et al., 2013). Furthermore, the single Hbl components form complexes in solution (Tausch et al., 2017). Again, the pore might not be completely formed due to the blocking of single components. Altogether, the system of pore-formation by $B$. cereus enterotoxins is highly complex and thus, also highly vulnerable to disruptive factors such as protein- or cell-binding food components.

The present study is another step toward our overall goal to identify patterns for risk assessment of foods contaminated with enteropathogenic $B$. cereus. So far, the enteropathogenic 
type is found mainly in milk and meat products, vegetables or soups, while emetic strains appear mostly in rice, pastry or pasta (Kramer and Gilbert, 1989; Shinagawa, 1990). The different foods could be divided into risk categories, according to criteria such as likelihood of contamination (see above), promotion of bacterial survival and growth before consumption (Gilbert et al., 1974), facilitation of survival during stomach passage (Clavel et al., 2004; Ceuppens et al., 2012b,c and this study) as well as influence on cytotoxic activity (Medrano et al., 2008, 2009 and this study).

\section{CONCLUSION}

Predicting the consumer's risk of $B$. cereus-contaminated foods is extremely difficult, as it depends on various factors. First, on the particular B. cereus strain, which can be characterized in detail by now (Jessberger et al., 2015, 2017). Equally important is the type of food the bacteria are ingested with, as it influences not only the number of bacteria entering the small intestine, but also

\section{REFERENCES}

Agata, N., Ohta, M., Mori, M., and Isobe, M. (1995). A novel dodecadepsipeptide, cereulide, is an emetic toxin of Bacillus cereus. FEMS Microbiol. Lett. 129, 17-20. doi: 10.1016/0378-1097(95)00119-P

Alpsoy, L., Agar, G., and Ikbal, M. (2009a). Protective role of vitamins A, C, and $\mathrm{E}$ against the genotoxic damage induced by aflatoxin B1 in cultured human lymphocytes. Toxicol. Ind. Health 25, 183-188. doi: 10.1177/074823370910 6068

Alpsoy, L., Yildirim, A., and Agar, G. (2009b). The antioxidant effects of vitamin A, C, and E on aflatoxin B1-induced oxidative stress in human lymphocytes. Toxicol. Ind. Health 25, 121-127. doi: 10.1177/074823370910 3413

Alpsoy, L., and Yalvac, M. E. (2011). Key roles of vitamins A, C, and E in aflatoxin B1-induced oxidative stress. Vitam. Horm. 86, 287-305. doi: 10.1016/B978-012-386960-9.00012-5

Anonymous. (2013). The European Union summary report on trends and sources of zoonoses, zoonotic agents and food-borne outbreaks 2011. EFSA J. 11:3129.

Beecher, D. J., Schoeni, J. L., and Wong, A. C. (1995). Enterotoxic activity of hemolysin BL from Bacillus cereus. Infect. Immun. 63, 4423-4428.

Berthold-Pluta, A., Pluta, A., and Garbowska, M. (2015). The effect of selected factors on the survival of Bacillus cereus in the human gastrointestinal tract. Microb. Pathog. 82, 7-14. doi: 10.1016/j.micpath.2015.03.015

Bottone, E. J. (2010). Bacillus cereus, a volatile human pathogen. Clin. Microbiol. Rev 23, 382-398. doi: 10.1128/CMR.00073-09

Brown, C. C., and Noelle, R. J. (2015). Seeing through the dark: new insights into the immune regulatory functions of vitamin A. Eur. J. Immunol. 45, 1287-1295. doi: 10.1002/eji.201344398

Ceuppens, S., Uyttendaele, M., Drieskens, K., Rajkovic, A., Boon, N., and Wiele, T. V. (2012a). Survival of Bacillus cereus vegetative cells and spores during in vitro simulation of gastric passage. J. Food Prot. 75, 690-694. doi: 10.4315/ 0362-028X.JFP-11-481

Ceuppens, S., Rajkovic, A., Hamelink, S., Van de Wiele, T., Boon, N., and Uyttendaele, M. (2012b). Enterotoxin production by Bacillus cereus under gastrointestinal conditions and their immunological detection by commercially available kits. Foodbor. Pathog. Dis. 9, 1130-1136. doi: 10.1089/fpd.2012. 1230

Ceuppens, S., Uyttendaele, M., Hamelink, S., Boon, N., and Van de Wiele, T. (2012c). Inactivation of Bacillus cereus vegetative cells by gastric acid and bile during in vitro gastrointestinal transit. Gut Pathog. 4, 11. doi: 10.1186/17574749-4-11

Chambial, S., Dwivedi, S., Shukla, K. K., John, P. J., and Sharma, P. (2013). Vitamin $\mathrm{C}$ in disease prevention and cure: an overview. Indian J. Clin. Biochem. 28, 314-328. doi: 10.1007/s12291-013-0375-3 the cytotoxic effect of the enterotoxins toward epithelial cells. According to these findings, food products could be divided into different risk categories.

\section{AUTHOR CONTRIBUTIONS}

CDR was responsible for spore preparation as well as for survival and cytotoxicity assays. $\mathrm{RD}$ and EM were involved in experimental setup and writing of the manuscript. NJ also conducted cytotoxicity assays and wrote the manuscript.

\section{FUNDING}

The IGF Project $18677 \mathrm{~N}$ of the FEI was supported via AiF within the program for promoting the Industrial Collective Research (IGF) of the German Ministry of Economic Affairs and Energy (BMWi), based on a resolution of the German Parliament.

Clavel, T., Carlin, F., Lairon, D., Nguyen-The, C., and Schmitt, P. (2004). Survival of Bacillus cereus spores and vegetative cells in acid media simulating human stomach. J. Appl. Microbiol. 97, 214-219. doi: 10.1111/j.1365-2672.2004.02292.x

Didier, A., Dietrich, R., Gruber, S., Bock, S., Moravek, M., Nakamura, T., et al. (2012). Monoclonal antibodies neutralize Bacillus cereus Nhe enterotoxin by inhibiting ordered binding of its three exoprotein components. Infect. Immun. 80, 832-838. doi: 10.1128/IAI.05681-11

Didier, A., Dietrich, R., and Märtlbauer, E. (2016). Antibody binding studies reveal conformational flexibility of the Bacillus cereus non-hemolytic enterotoxin (Nhe) A-Component. PLoS One 11:e0165135. doi: 10.1371/journal.pone. 0165135

Dietrich, R., Fella, C., Strich, S., and Märtlbauer, E. (1999). Production and characterization of monoclonal antibodies against the hemolysin BL enterotoxin complex produced by Bacillus cereus. Appl. Environ. Microbiol. 65, 4470-4474.

Dietrich, R., Moravek, M., Burk, C., Granum, P. E., and Märtlbauer, E. (2005). Production and characterization of antibodies against each of the three subunits of the Bacillus cereus nonhemolytic enterotoxin complex. Appl. Environ. Microbiol. 71, 8214-8220. doi: 10.1128/AEM.71.12.8214-8220.2005

Ehling-Schulz, M., Fricker, M., and Scherer, S. (2004). Bacillus cereus, the causative agent of an emetic type of food-borne illness. Mol. Nutr. Food Res. 48, 479-487. doi: 10.1002/mnfr.200400055

Ghelardi, E., Celandroni, F., Salvetti, S., Ceragioli, M., Beecher, D. J., Senesi, S., et al. (2007). Swarming behavior of and hemolysin BL secretion by Bacillus cereus. Appl. Environ. Microbiol. 73, 4089-4093. doi: 10.1128/AEM.02345-06

Gilbert, R. J., Stringer, M. F., and Peace, T. C. (1974). The survival and growth of Bacillus cereus in boiled and fried rice in relation to outbreaks of food poisoning. J. Hyg. Camb. 73:433-444. doi: 10.1017/S0022172400042790

Heilkenbrinker, U., Dietrich, R., Didier, A., Zhu, K., Lindbäck, T., Granum, P. E., et al. (2013). Complex formation between NheB and NheC is necessary to induce cytotoxic activity by the three-component Bacillus cereus Nhe enterotoxin. PLoS One 8:e63104. doi: 10.1371/journal.pone.0063104

Jessberger, N., Dietrich, R., Bock, S., Didier, A., and Märtlbauer, E. (2014). Bacillus cereus enterotoxins act as major virulence factors and exhibit distinct cytotoxicity to different human cell lines. Toxicon 77, 49-57. doi: 10.1016/j. toxicon.2013.10.028

Jessberger, N., Krey, V. M., Rademacher, C., Böhm, M. E., Mohr, A. K., EhlingSchulz, M., et al. (2015). From genome to toxicity: a combinatory approach highlights the complexity of enterotoxin production in Bacillus cereus. Front. Microbiol. 6:560. doi: 10.3389/fmicb.2015.00560

Jessberger, N., Rademacher, C., Krey, V. M., Dietrich, R., Mohr, A. K., Böhm, M. E., et al. (2017). Simulating intestinal growth conditions enhances toxin production of enteropathogenic Bacillus cereus. Front. Microbiol. 8:627. doi: $10.3389 /$ fmicb.2017.00627 
Kniehl, E., Becker, A., and Forster, D. H. (2003). Pseudo-outbreak of toxigenic Bacillus cereus isolated from stools of three patients with diarrhoea after oral administration of a probiotic medication. J. Hosp. Infect. 55, 33-38. doi: 10. 1016/S0195-6701(03)00133-6

Kramer, J. M., and Gilbert, R. J. (1989). “Bacillus cereus and other Bacillus species,” in Food Borne Bacterial Pathogens, ed. M. P. Doyle (New York, NY: Marcel Dekker), 21-70.

Latorre, D., Puddu, P., Valenti, P., and Gessani, S. (2010). Reciprocal interactions between lactoferrin and bacterial endotoxins and their role in the regulation of the immune response. Toxins (Basel) 2, 54-68. doi: 10.3390/toxins2010054

Luna-Castro, S., Aguilar-Romero, F., Samaniego-Barron, L., Godinez-Vargas, D., and de la Garza, M. (2014). Effect of bovine apo-lactoferrin on the growth and virulence of Actinobacillus pleuropneumoniae. Biometals 27, 891-903. doi: 10.1007/s10534-014-9752-5

Lund, T., De Buyser, M. L., and Granum, P. E. (2000). A new cytotoxin from Bacillus cereus that may cause necrotic enteritis. Mol. Microbiol. 38, 254-261. doi: 10.1046/j.1365-2958.2000.02147.x

Lund, T., and Granum, P. E. (1996). Characterisation of a non-haemolytic enterotoxin complex from Bacillus cereus isolated after a foodborne outbreak. FEMS Microbiol. Lett. 141, 151-156. doi: 10.1111/j.1574-6968.1996.tb08377.x

May, J. M., and Qu, Z. C. (2010). Chelation of intracellular iron enhances endothelial barrier function: a role for vitamin C? Arch. Biochem. Biophys. 500, 162-168. doi: 10.1016/j.abb.2010.05.022

May, J. M., and Qu, Z. C. (2011). Ascorbic acid prevents oxidant-induced increases in endothelial permeability. Biofactors 37, 46-50. doi: 10.1002/biof.134

Mazzantini, D., Celandroni, F., Salvetti, S., Gueye, S. A., Lupetti, A., Senesi, S., et al. (2016). FlhF is required for swarming motility and full pathogenicity of Bacillus cereus. Front. Microbiol. 7:1644. doi: 10.3389/fmicb.2016.01644

Mead, P. S., Slutsker, L., Dietz, V., McCaig, L. F., Bresee, J. S., Shapiro, C., et al. (1999). Food-related illness and death in the United States. Emerg. Infect. Dis. 5, 607-625. doi: 10.3201/eid0505.990502

Medrano, M., Hamet, M. F., Abraham, A. G., and Perez, P. F. (2009). Kefiran protects Caco-2 cells from cytopathic effects induced by Bacillus cereus infection. Antonie Van Leeuwenhoek 96, 505-513. doi: 10.1007/s10482-0099366-z

Medrano, M., Perez, P. F., and Abraham, A. G. (2008). Kefiran antagonizes cytopathic effects of Bacillus cereus extracellular factors. Int. J. Food Microbiol. 122, 1-7. doi: 10.1016/j.ijfoodmicro.2007.11.046

Merritt, E. A., and Hol, W. G. (1995). AB5 toxins. Curr. Opin. Struct. Biol. 5, 165-171. doi: 10.1016/0959-440X(95)80071-9

Messelhäusser, U., Frenzel, E., Blochinger, C., Zucker, R., Kampf, P., and EhlingSchulz, M. (2014). Emetic Bacillus cereus are more volatile than thought: recent foodborne outbreaks and prevalence studies in Bavaria (2007-2013). Biomed. Res. Int. 2014:465603. doi: 10.1155/2014/465603

Minnaard, J., Lievin-Le Moal, V., Coconnier, M. H., Servin, A. L., and Perez, P. F. (2004). Disassembly of F-actin cytoskeleton after interaction of Bacillus cereus with fully differentiated human intestinal Caco-2 cells. Infect. Immun. 72, 3106-3112. doi: 10.1128/IAI.72.6.3106-3112.2004

Ochoa, T. J., and Cleary, T. G. (2009). Effect of lactoferrin on enteric pathogens. Biochimie 91, 30-34. doi: 10.1016/j.biochi.2008.04.006

Ramarao, N., and Lereclus, D. (2006). Adhesion and cytotoxicity of Bacillus cereus and Bacillus thuringiensis to epithelial cells are FlhA and PlcR dependent, respectively. Microbes Infect. 8, 1483-1491. doi: 10.1016/j.micinf.2006.01.005

Rivera, F. P., Medina, A. M., Bezada, S., Valencia, R., Bernal, M., Meza, R., et al. (2013). Bovine lactoferrin decreases cholera-toxin-induced intestinal fluid accumulation in mice by ganglioside interaction. PLoS One 8:e59253. doi: 10.1371/journal.pone.0059253

Salvetti, S., Ghelardi, E., Celandroni, F., Ceragioli, M., Giannessi, F., and Senesi, S. (2007). FlhF, a signal recognition particle-like GTPase, is involved in the regulation of flagellar arrangement, motility behaviour and protein secretion in Bacillus cereus. Microbiology 153(Pt 8), 2541-2552. doi: 10.1099/mic.0.2006/ 005553-0

Sanz-Puig, M., Pina-Perez, M. C., Criado, M. N., Rodrigo, D., and MartinezLopez, A. (2015). Antimicrobial potential of cauliflower, broccoli, and okara byproducts against foodborne bacteria. Foodborne Pathog. Dis. 12, 39-46. doi: $10.1089 / \mathrm{fpd} .2014 .1801$
Sastalla, I., Fattah, R., Coppage, N., Nandy, P., Crown, D., Pomerantsev, A. P., et al. (2013). The Bacillus cereus $\mathrm{Hbl}$ and Nhe tripartite enterotoxin components assemble sequentially on the surface of target cells and are not interchangeable. PLoS One 8:e76955. doi: 10.1371/journal.pone.0076955

Sato, N., Kurotaki, H., Ikeda, S., Daio, R., Nishinome, N., Mikami, T., et al. (1999). Lactoferrin inhibits Bacillus cereus growth and heme analogs recover its growth. Biol. Pharm. Bull. 22, 197-199. doi: 10.1248/bpb.22.197

Scallan, E., Griffin, P. M., Angulo, F. J., Tauxe, R. V., and Hoekstra, R. M. (2011). Foodborne illness acquired in the United States-unspecified agents. Emerg. Infect. Dis. 17, 16-22. doi: 10.3201/eid1701.091101p2

Shinagawa, K. (1990). Analytical methods for Bacillus cereus and other Bacillus species. Int. J. Food Microbiol. 10, 125-141. doi: 10.1016/0168-1605(90)90 061-9

Sirisinha, S. (2015). The pleiotropic role of vitamin A in regulating mucosal immunity. Asian Pac. J. Allergy Immunol. 33, 71-89.

Sorice, A., Guerriero, E., Capone, F., Colonna, G., Castello, G., and Costantini, S. (2014). Ascorbic acid: its role in immune system and chronic inflammation diseases. Mini Rev. Med. Chem. 14, 444-452. doi: 10.2174/1389557514666140428112602

Stenfors Arnesen, L. P., Fagerlund, A., and Granum, P. E. (2008). From soil to gut: Bacillus cereus and its food poisoning toxins. FEMS Microbiol. Rev. 32, 579-606. doi: 10.1111/j.1574-6976.2008.00112.x

Ströhle, A., Wolters, M., and Hahn, A. (2011). Micronutrients at the interface between inflammation and infection-ascorbic acid and calciferol: part 1, general overview with a focus on ascorbic acid. Inflamm. Allergy Drug Targets 10, 54-63. doi: 10.2174/187152811794352105

Tabak, M., Armon, R., Rosenblat, G., Stermer, E., and Neeman, I. (2003). Diverse effects of ascorbic acid and palmitoyl ascorbate on Helicobacter pylori survival and growth. FEMS Microbiol. Lett. 224, 247-253. doi: 10.1016/S0378-1097(03) 00439-7

Tausch, F., Dietrich, R., Schauer, K., Janowski, R., Niessing, D., Märtlbauer, E., et al. (2017). Evidence for complex formation of the Bacillus cereus haemolysin BL components in solution. Toxins (Basel) 9:E288. doi: 10.3390/toxins909 0288

Valenti, P., and Antonini, G. (2005). Lactoferrin: an important host defence against microbial and viral attack. Cell Mol. Life. Sci. 62, 2576-2587. doi: 10.1007/ s00018-005-5372-0

Valenti, P., Berlutti, F., Conte, M. P., Longhi, C., and Seganti, L. (2004). Lactoferrin functions: current status and perspectives. J. Clin. Gastroenterol. 38 6(Suppl.), S127-S129. doi: 10.1097/01.mcg.0000128941.46881.33

Wijnands, L. M., Dufrenne, J. B., van Leusden, F. M., and Abee, T. (2007). Germination of Bacillus cereus spores is induced by germinants from differentiated Caco-2 Cells, a human cell line mimicking the epithelial cells of the small intestine. Appl. Environ. Microbiol. 73, 5052-5054. doi: 10.1128/AEM. 02390-06

Wijnands, L. M., Dufrenne, J. B., Zwietering, M. H., and van Leusden, F. M. (2006). Spores from mesophilic Bacillus cereus strains germinate better and grow faster in simulated gastro-intestinal conditions than spores from psychrotrophic strains. Int. J. Food Microbiol. 112, 120-128. doi: 10.1016/j.ijfoodmicro.2006. 06.015

Wijnands, L. M., Pielaat, A., Dufrenne, J. B., Zwietering, M. H., and van Leusden, F. M. (2009). Modelling the number of viable vegetative cells of Bacillus cereus passing through the stomach. J. Appl. Microbiol. 106, 258-267. doi: 10.1111/j. 1365-2672.2008.03999.x

Conflict of Interest Statement: The authors declare that the research was conducted in the absence of any commercial or financial relationships that could be construed as a potential conflict of interest.

Copyright (C) 2018 Da Riol, Dietrich, Märtlbauer and Jessberger. This is an openaccess article distributed under the terms of the Creative Commons Attribution License (CC BY). The use, distribution or reproduction in other forums is permitted, provided the original author(s) and the copyright owner(s) are credited and that the original publication in this journal is cited, in accordance with accepted academic practice. No use, distribution or reproduction is permitted which does not comply with these terms. 